\title{
Evaluation of load capacity of gears with an asymmetric tooth profile
}

\author{
Tomoya Masuyama* and Naoki Miyazaki
}

\begin{abstract}
Background: An ISO standard tooth profile has a symmetric pressure angle of $20^{\circ}$. However, the load capacity can be increased with respect to bending and contact pressure by increasing the pressure angle on the meshing side of an asymmetric tooth. Accordingly, we analyzed the torque transmission capacity of asymmetric gears with various pressure angles.

Methods: We calculated the deflection and bending stress of teeth by the finite element method and found the root stress taking into account the load-sharing ratio. Hertzian contact stress was calculated with respect to contact pressure. Normal vector load was converted into a torque, and torque capacity was evaluated when the stress reached the allowable stress for each case.

Results: Reduced bending stress because of an increase in tooth thickness and decreased transmission torque because of a reduction in the base circle radius work together to maximize the load capacity for bending at a pressure angle of around $30^{\circ}$. Maximum load capacity with respect to contact pressure is achieved when the pressure angle is made $45^{\circ}$ by increasing the radius of the contact surface.

Conclusions: Both strength with respect to bending and contact pressure are found, and the torque transmission capacity of the gear is determined by the lower value of the two. For low-strength materials such as flame-hardened steel, damage due to contact pressure is expected for all forms of gears and the greatest torque capacity was at a pressure angle of $45^{\circ}$. In the case of assuming $800 \mathrm{Hv}$ and an inclusion size $\sqrt{A}=50 \mu \mathrm{m}$ for a high-strength material, the greatest torque transmission capacity is obtained at a pressure angle of $30^{\circ}$. In the case of assuming a moderatestrength material such as case-hardened steel, an optimal form exists at which strength with respect to bending and strength with respect to contact pressure are equal.
\end{abstract}

Keywords: Gear, Pressure angle, Asymmetric tooth profile, Strength, Torque capacity, Stress

\section{Background}

The ISO standards specify a symmetric form and a pressure angle of $20^{\circ}$ for a standard rack tool. However, as the pressure angle increases past $20^{\circ}$, the bending strength can be expected to increase because of the increase in the tooth root thickness, and the contact pressure strength can be expected to increase because of the larger profile radius of curvature. Furthermore, although a pressure angle sufficiently greater than the limit of the tooth tip cannot be achieved, this can be solved by making the pressure angle on each side of the tooth asymmetric. Unidirectional torque transfer is the principal

\footnotetext{
* Correspondence: masu@tsuruoka-nct.ac.jp

Mechanical Engineering course, National Institute of Technology, Tsuruoka College, Sawada 104, Ino-oka, Tsuruoka 997-8511, Japan
}

factor in general gearing, so there may be some issues with the strength on the low-pressure side being weaker.

Kapelevich and co-workers conducted a series of studies on asymmetric gears. In 2000, they indicated that an asymmetric gear with a higher pressure angle on the drive side would allow for an increase in load capacity while reducing weight (Kapelevich, 2000). In the same year, Litvin et al. (2000) analyzed the bending and contact stresses of an asymmetric gear tooth. They demonstrated the mitigating bending stress through the optimization of tooth profile (Kapelevich and Shekhtman, 2009). Kapelevich has integrated his exemplary work in book form (Kapelevich, 2013). A recent study by the same group has calculated both bending stress and contact pressure using three-dimensional finite element (FE) 
analysis to compare with a symmetric tooth profile (Kapelevich and Shekhtman, 2016).

Deng and co-workers carried out a stress analysis of an asymmetric gear with the aim of increasing the bending load capacity by increasing the tooth thickness. They achieved an increase in tooth thickness by increasing the pressure angle on the reverse side (Deng et al. 2003). Kruger et al. (2013) used a boundary element method to calculate the stress distribution of an asymmetric tooth, the stress state when an adjacent tooth is loaded, and the influence of plastic deformation due to the generation of a high compressive stress in the deep section of the load point. We found a bending stress distribution by using the finite element method (FEM) and used the result to conduct a strength simulation focusing on an inclusion distribution (Masuyama et al., 2015).

Nevertheless, there are fewer papers that focus on the between-normal vector load and the transmission torque according to changes in pressure angle in a wider range. Accordingly, in the present study, we conducted detailed strength evaluations on an asymmetric gear, performed an FEM analysis, and found the change in load-sharing ratio as a result of rotation. We then calculated the bending stress and Hertzian contact stress and evaluated the difference in torque transmission capacity according to materials.

\section{Methods}

\section{Asymmetric tooth profiles}

The tooth profiles considered in the present study were created with a rack cutter. The profile of ISO standard teeth (ISO53, 1998) is determined as indicated in Fig. 1. The tooth profiles treated in the present study had various left/right pressure angles and tool tooth tip radii.

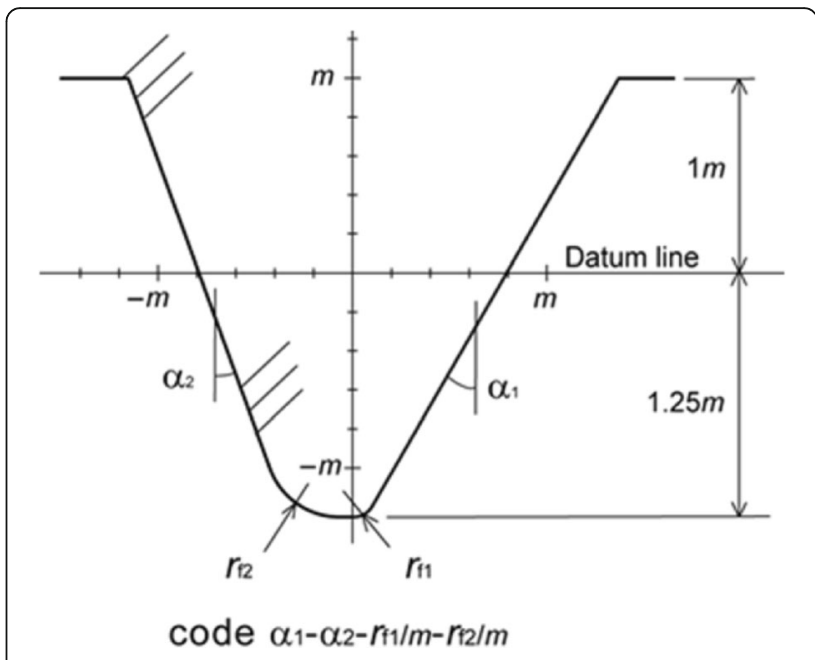

Fig. 2 Example of tool parameters

The dedendum and the addendum of the cutter were 1 and $1.25 \mathrm{~m}$, respectively.

Let the pressure angle be $\alpha_{1}$ and the tool tooth tip radius be $r_{1} m$ for the right side of the rack surface that creates the load-side tooth surface of the gear. Let the pressure angle be $\alpha_{2}$ and the tooth tip radius be $r_{2} m$ for the left side of the rack surface that creates the reverseside tooth of the gear. Then, in this paper, the forms of teeth are described using $\alpha_{1}-\alpha_{2}-r_{1}-r_{2}$ as shown in Fig. 2. The step in pressure angle change was $1^{\circ}$, and the step in tooth tip radius was $0.01 \mathrm{~mm}$. The tooth profiles were generated by rolling the datum line for the rack shown in Fig. 3 against a gear-cutting pitch circle.

Figure 4 shows the tooth profiles that were created. In this paper, the number of teeth is 18 and the tooth module is $5 \mathrm{~mm}$ for the analytical model of the gears. Six

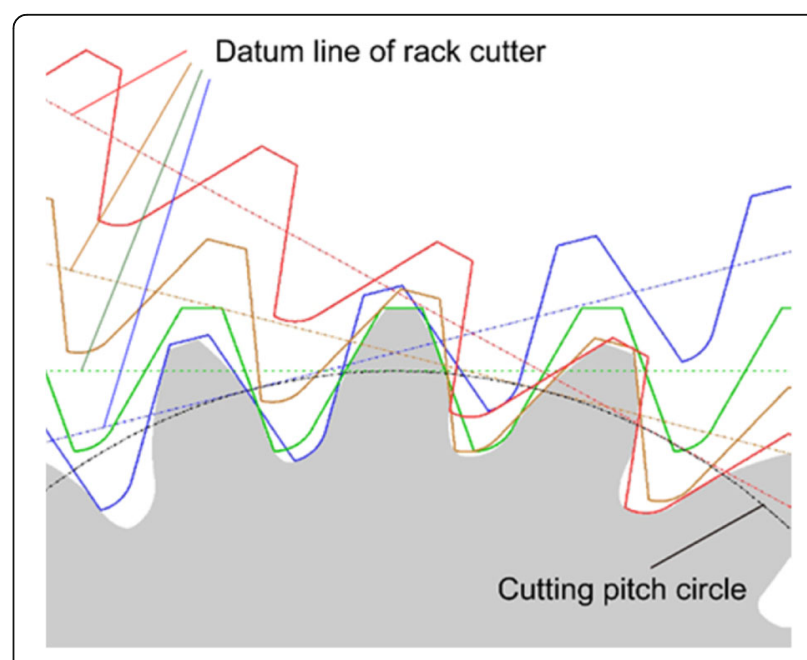

Fig. 3 Illustration of tooth generation by a rack cutter

Fig. 1 ISO standard rack profile 


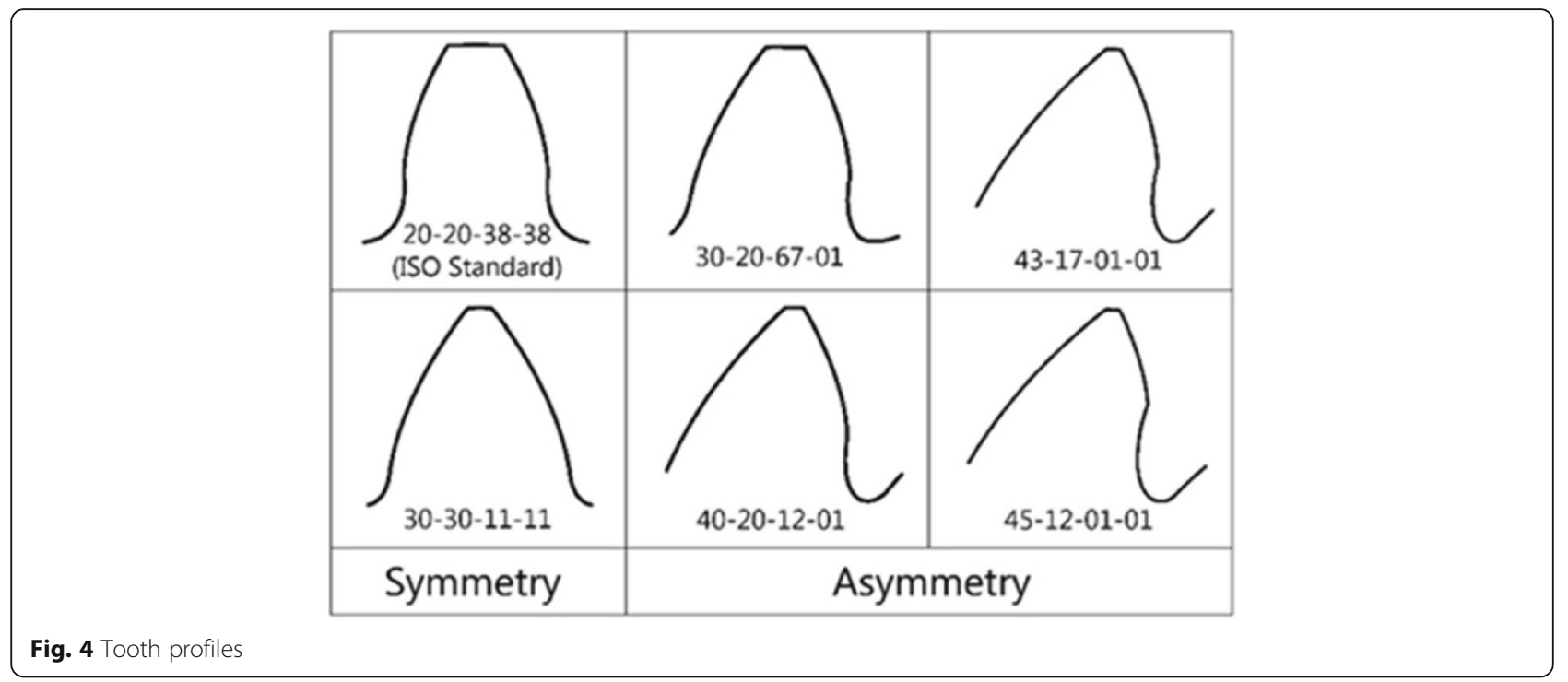

tooth varieties were prepared: (1) the ISO standard tooth form 20-20-38-38; (2) 30-30-11-11, which had a large pressure angle while keeping the symmetric form; (3) 30-20-67-01 and (4) 40-20-12-01, which had the reverseside pressure angle set at $20^{\circ}$ and just the mesh-side pressure angle increased; (5) 43-17-01-01, which had a reverse-side pressure angle of $17^{\circ}$ (the limit at which an undercut does not occur with 18 teeth) and which achieves the greatest pressure angle on the meshing side at this time; and (6) 45-12-01-01, which, although undercut occurs with 18 teeth, has the smallest pressure angle at which reverse operation is possible because the meshing ratio exceeds 1 . Also, the tooth tip radius was made the largest size at which gaps do not occur.

\section{Finite element model}

Based on the outline of the tooth profiles shown in Fig. 4, nodes were arranged appropriately within the teeth and quadrilateral elements were generated by the Delaunay method (Taniguchi, 1992). At this time, several elements were automatically supplemented to give the elements an appropriate form. To prevent the number of elements from becoming excessive, only three teeth were created and the rest of the gear was made a cylindrical form. The gear was given a shaft hole of diameter $40 \mathrm{~mm}$, and the nodes on the shaft hole were given fixed boundary conditions in the FEM analysis. Figure 5 shows an example of the generated elements.

In this paper, we wish to calculate the stress distribution of a tooth having demonstrated the load-sharing ratio. Accordingly, a concentrated load in the normal direction was applied to each point on five equal lengths from the meshing origin to the lowest point of singletooth contact (LPSTC) on the line of action; to each point on five equal lengths from the highest point of single-tooth contact (HPSTC) to the tooth tip; and on the pitch points. Figure 6 shows the positions on the line of action and the loading point. The loading points on the tooth profile are indicated in Fig. 7. The number of teeth on the mating gear was set to 25 .

\section{Results and discussion}

\section{Load-sharing ratio}

When a concentrated load is applied to a tooth surface, a deformation is produced as in Figs. 8 and 9. Figure 8 indicates the deflection of tooth 30-20-67-01 for each

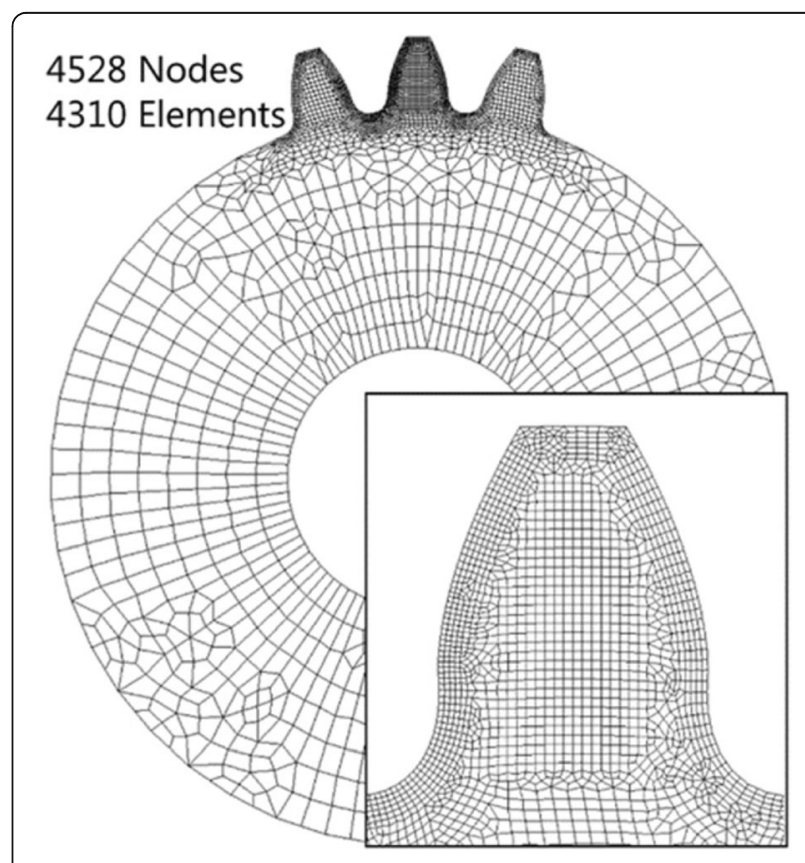

Fig. 5 Example of FEM model 


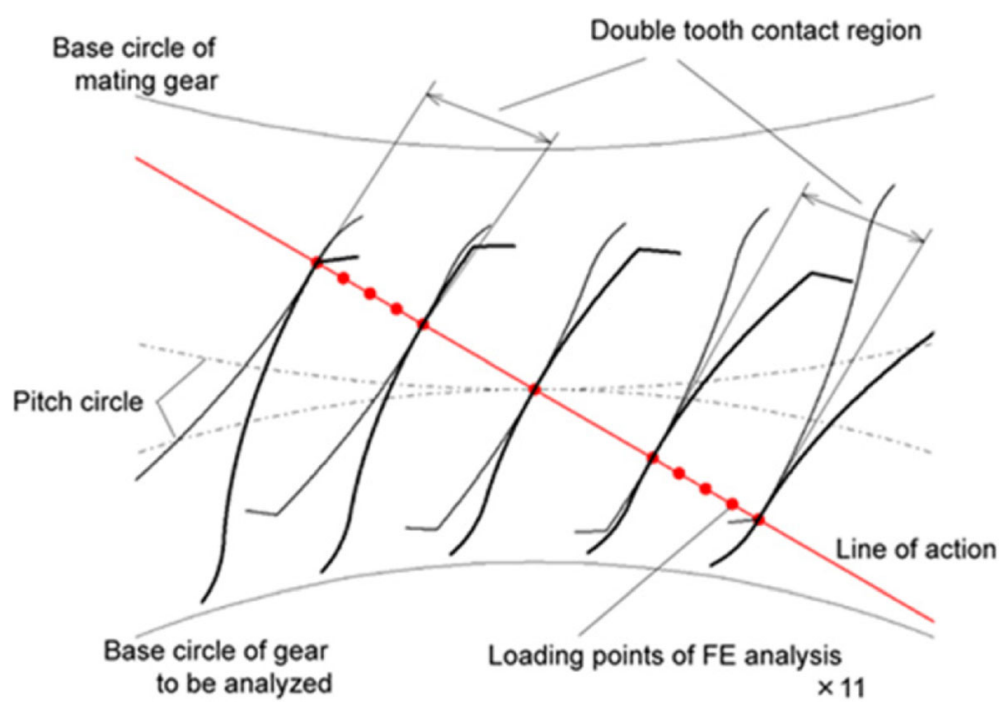

Fig. 6 Relationship between meshing and loading points

loading point when a unit-concentrated load is applied. Figure 9 shows the deformation when a load is applied on the HPSTC.

The load-sharing ratio was found from the tooth deflection by the following process. The left diagram in Fig. 10 shows the condition of two-tooth meshing. At this time, the size of the load shared by the t11-t21 pair and the t12-t22 pair can be solved as a statically indeterminate problem using a model as shown in the right diagram. In the right model diagram, let $F_{1}$ be the force acting on $\mathrm{t} 11$ and $\mathrm{t} 21$, and let $F_{2}$ be the force acting on $\mathrm{t} 12$ and $\mathrm{t} 22$. If the bending rigidity of the tooth is $k_{11}$ to $k_{22}$, then the following equation holds true statically from the equilibria of forces and deflection conditions:

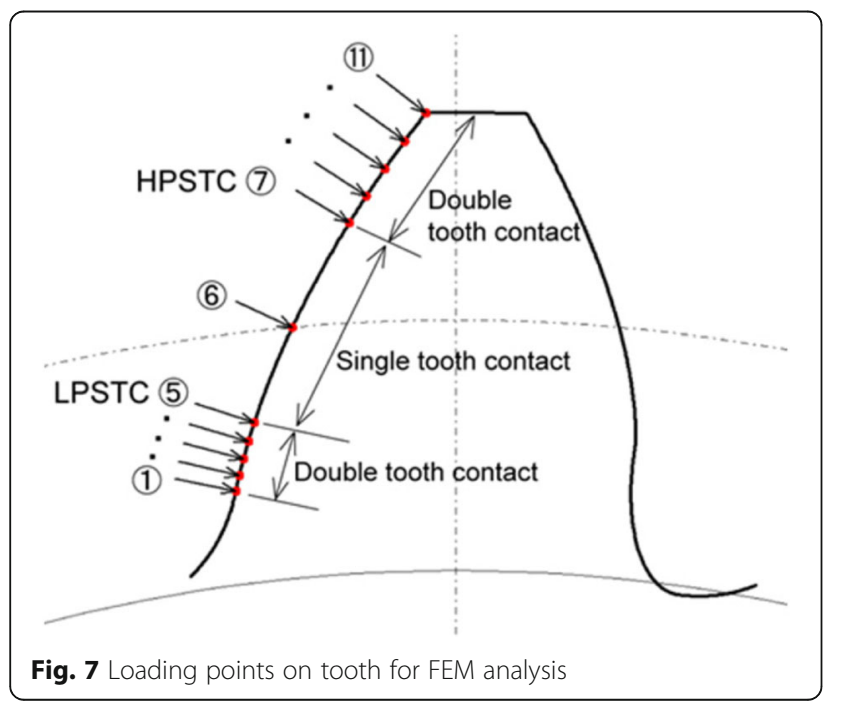

$$
\begin{aligned}
& F_{1}\left(\frac{1}{k_{11}}+\frac{1}{k_{21}}\right)=\left(\frac{1}{k_{12}}+\frac{1}{k_{22}}\right) \\
& F_{1}+F_{2}=F
\end{aligned}
$$

Previous studies treated the displacement at the intersection of the tooth-form central line and the line of action of the normal vector load as the deflection when evaluating the bending rigidity of a tooth (Deng et al. 2003). However, the above intersection cannot be defined for an asymmetric tooth in the case in which the tooth is extremely inclined, as in Fig. 11. Also, the error due to the FEM calculation of the displacement of the point of surface is large. Accordingly, the displacement in the direction of the line of action at a point $1 \mathrm{~mm}$ under the surface, as shown in Fig. 11, was taken as the deflection.

Figure 12 shows the change in stiffness as a result of the change in meshing position. A tendency is found for the stiffness to increase with pressure angle on the load side. This is because the thickness of the tooth root increases and the vertical component of force with respect to the tooth-form central line decreases. Tooth 43-1701-01 is generally similar to tooth 45-12-01-01 and is omitted to simplify the diagram. Figure 12 gives the results for 18 teeth; the same calculation was performed for a gear of 25 teeth. Figure 13 shows the calculation results for the load-sharing ratios based on Eq. (1). Teeth 43-17-01-01 and 30-30-11-11 are almost the same as teeth 45-12-01-01 and 30-20-12-01, respectively and are omitted from the diagram. The load-sharing ratio in the two-tooth meshing region is around 40-60\% for all gears, and no significant difference according to tooth form was observed. 


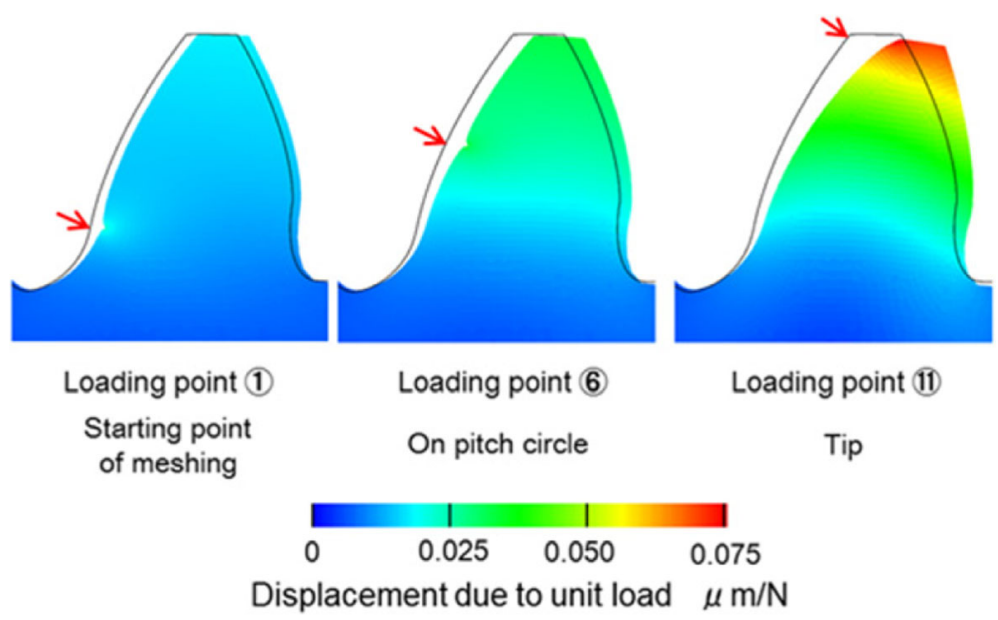

Fig. 8 Example of tooth deflection for each loading point

\section{Stress analysis}

Failure of a gear tooth is generally divided into bending fracture and tooth surface damage. The former is caused by bending stress on the root and the latter by contact pressure. Accordingly, we calculated the root stress and Hertzian contact stress by the tooth surface normal vector load, taking into account the load-sharing ratio.

\section{Bending stress}

As the position of the load moves from the start point of meshing to the tooth tip, the bending moment increases with respect to unit-concentrated load, and the bending stress of the tooth root increases correspondingly. However, the present study evaluated the root stress taking into account the load-sharing ratio.

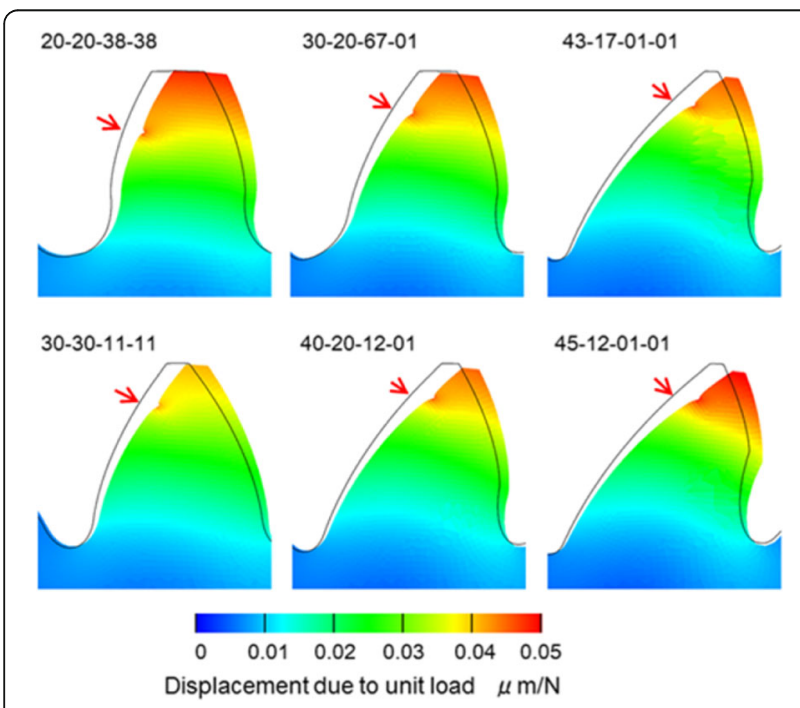

Fig. 9 Deflection of tooth with HPSTC loading for each tooth profile
Figure 14 summarizes the tooth root maximum bending stress $\sigma_{1 \max }$ with respect to each load point with unit-concentrated load $\times$ load-sharing ratio as a boundary condition, using the load-sharing ratios shown in Fig. 13. Since tooth root thickness and the component of the load in the radial direction increase because of the increased pressure angle, bending stress with respect to the same normal vector load decreases. In all cases, it was found that the bending stress of the tooth root reaches a maximum at the highest point of single-tooth contact. Tooth 43-17-01-01 is generally similar to 45-1201-01 and is omitted. Figure 15 shows the distribution of maximum principal stress $\sigma_{1}$ when a unit-concentrated load is applied on the HPSTC.

\section{Contact stress}

We calculated the Hertzian contact stress under the meshing point in order to evaluate the load capacity for tooth surface damage. The stress distribution under the surface is the issue with regard to Hertzian stress, so it is acceptable to consider it a problem of contact between two cylinders. Accordingly, the pressure angle on the reverse side and the tool tooth tip radius have no effect in the discussion of this section. The maximum Hertzian contact pressure $p_{\max }$ is expressed by Eq. (2):

$$
p_{\text {max }}=\sqrt{\frac{1}{\pi} \frac{P_{n}}{b} \frac{\frac{1}{R_{1}}+\frac{1}{R_{2}}}{\frac{1-v_{1}^{2}}{E_{1}}+\frac{1-v_{2}^{2}}{E_{2}}}}
$$

Here, $P_{\mathrm{n}}$ is the contact load, $b$ is the contact width, $R$ is the curvature radius, $v$ is Poisson's ratio, $E$ is Young's modulus, and subscripts 1 and 2 indicate the gear of the analytical object and the mating gear, respectively. In this section, a Young's modulus of $206 \mathrm{GPa}$ and a Poisson ratio of 0.3 were adopted. The contact width was made a 

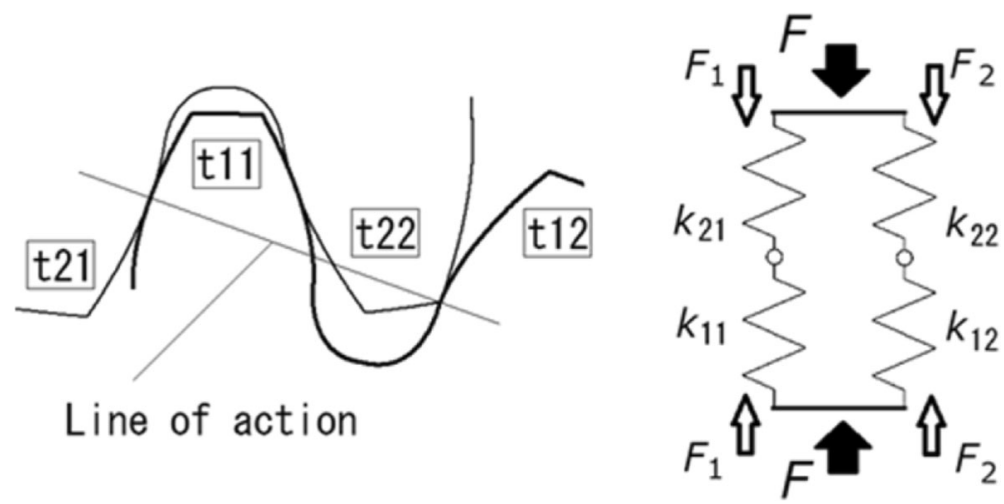

Fig. 10 Spring model of teeth

unit width of $1 \mathrm{~mm}$. Figure 16 shows the maximum pressure $p_{\max }$ under the condition of a contact load $P_{\mathrm{n}}=1000 \mathrm{~N} \times$ load-sharing ratio.

Excluding the case of a pressure angle of $20^{\circ}$, the maximum contact stress was at the lowest point of single-tooth contact. For a pressure angle of $20^{\circ}$, the relative curvature is large in the vicinity of the tooth root, as shown in Fig. 17, making the Hertzian stress a maximum at the point at which meshing commenced as a result. Here, the relative curvature $1 / R=$ $1 / R_{1}+1 / R_{2}$ was found for meshing with a mating gear of tooth number $Z_{2}=25$.

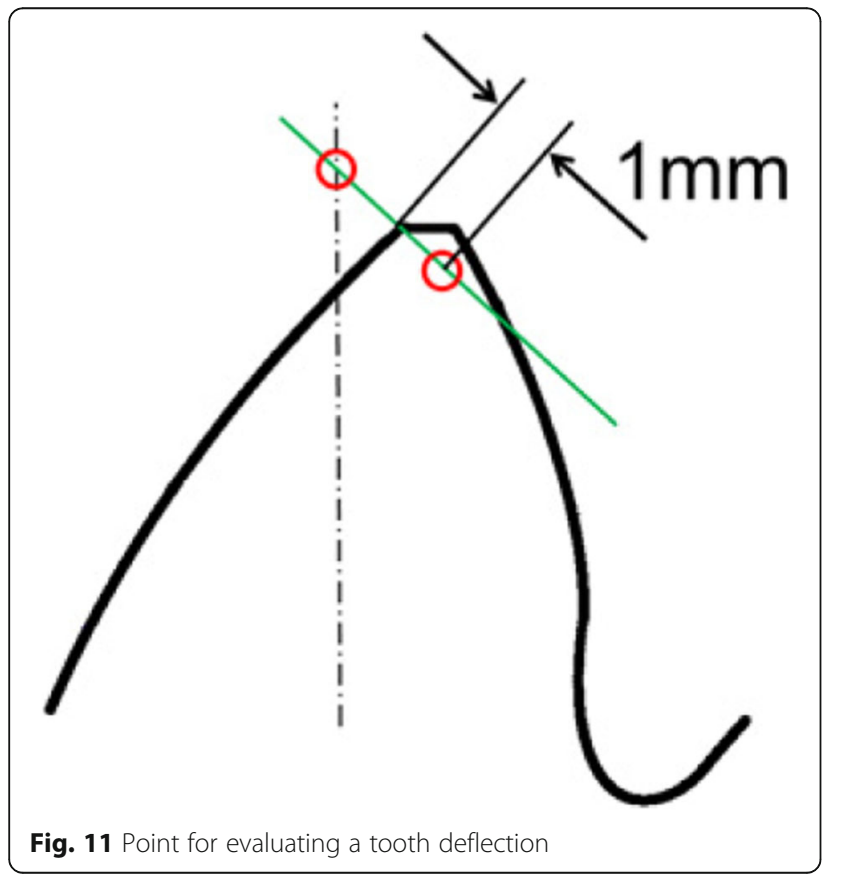

\section{Estimation of allowable stress}

Assuming the manufacture of asymmetric tooth forms with various materials, we determined the allowable stress using values stipulated in ISO6336-5 (ISO6336-5, 2003) and a strength evaluation formula that we proposed.

From ISO standards for the allowable stress, we selected a flame-hardened MQ class steel with $\sigma_{\text {Flim }}=360 \mathrm{MPa}$ for bending and $\sigma_{\mathrm{Hlim}}=1150 \mathrm{MPa}$ for surface damage. Similarly, $\sigma_{\text {Flim }}=525 \mathrm{MPa}$ and $\sigma_{\text {Hlim }}=1650 \mathrm{MPa}$ were adopted for the allowable stress of a case-hardened ME class steel.

Referring to Murakami's theory (Murakami, 2002) that the fatigue strength of high-strength material depends on the hardness of the material and the size of material defects contained within it, we proposed Eqs. (3) (Masuyama et al. 2002) and (4) (Narita et al. 2013) from the results of experiments on the bending fatigue of a gear and on the surface damage of a steel roller:

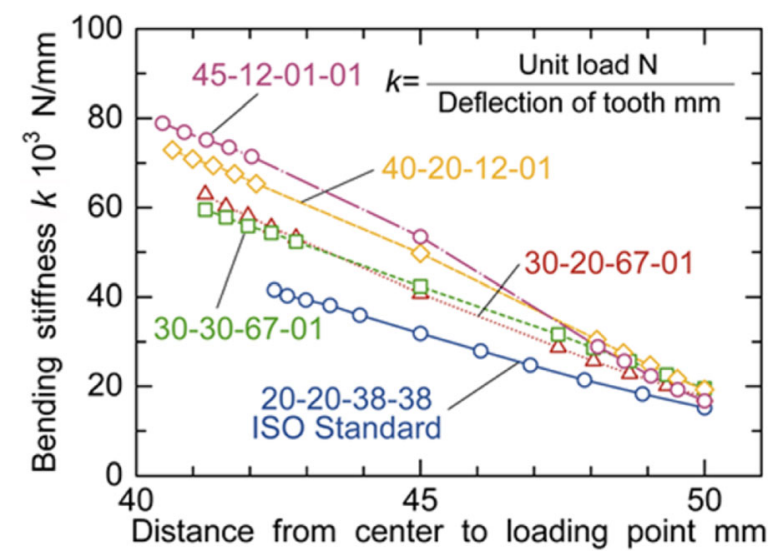

Fig. 12 Bending stiffness of teeth 


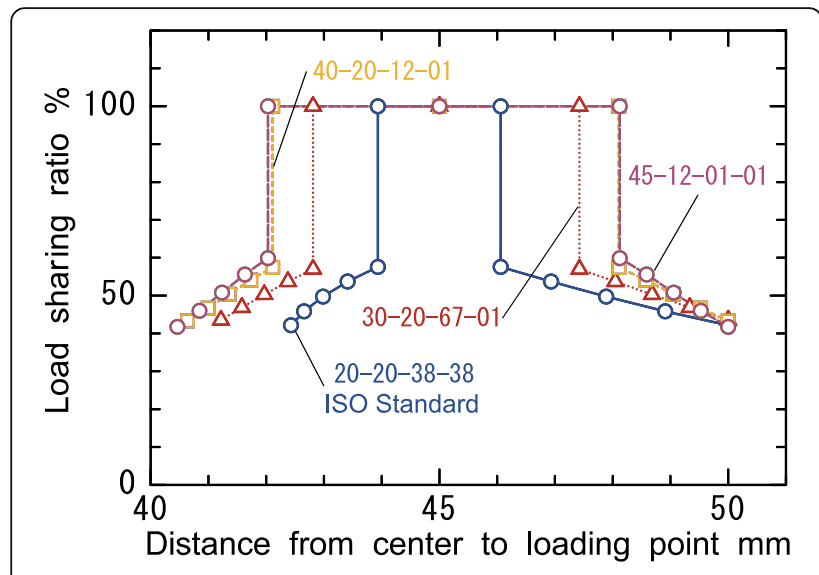

Fig. 13 Load-sharing ratio of gears

$$
\begin{aligned}
\sigma_{w} & =\frac{0.98\left(H_{V}+120\right)}{(\sqrt{A})^{1 / 6}}\left[\frac{1}{2}\right]^{\alpha} \\
\alpha & =0.226+H_{V} \times 10^{-4} \\
\tau_{w} & =0.97 \times \frac{1.56\left(H_{V}+120\right)}{(\sqrt{A})^{1 / 6}}
\end{aligned}
$$

Here, $H_{v}$ is the Vickers hardness of the material and $A$ is the projected area of defects contained in the material. In this paper, we assume hardened steel as the gear material. Accordingly, the allowable stress was found for two types of material of hardness 600 and $800 \mathrm{Hv}$, assuming an inclusion size $\sqrt{A}=50 \mu \mathrm{m}$.

In Eq. (3), $\sigma_{\mathrm{w}}$ is the stress amplitude for the bending fatigue limit. Therefore, the allowable stress for bending, $\sigma_{\text {Flim }}$, is expressed by

$$
\sigma_{\text {Flim }}=2 \times \sigma_{w}
$$

Likewise in Eq. (4), the stress component of the surface fatigue limit $\tau_{\mathrm{w}}$ is $\tau_{\mathrm{zx}}$, which is the shearing stress parallel

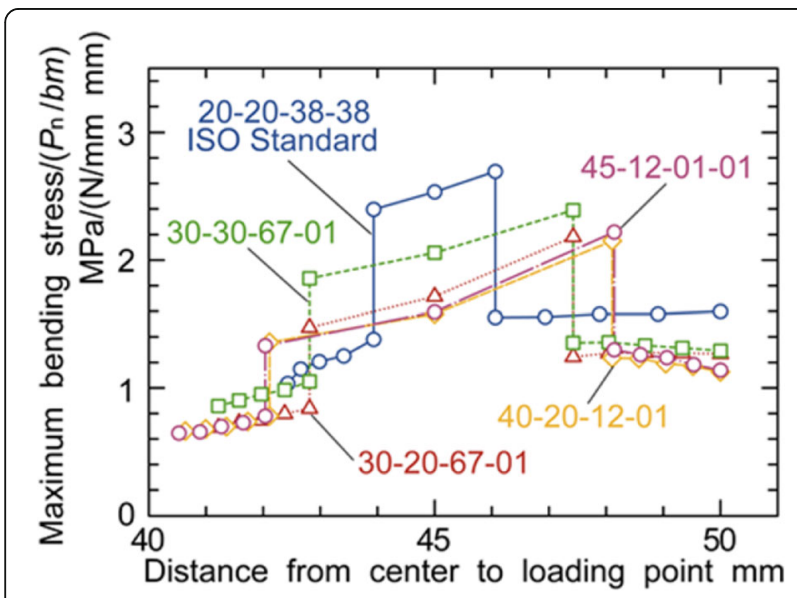

Fig. 14 Bending stress considering load-sharing ratio

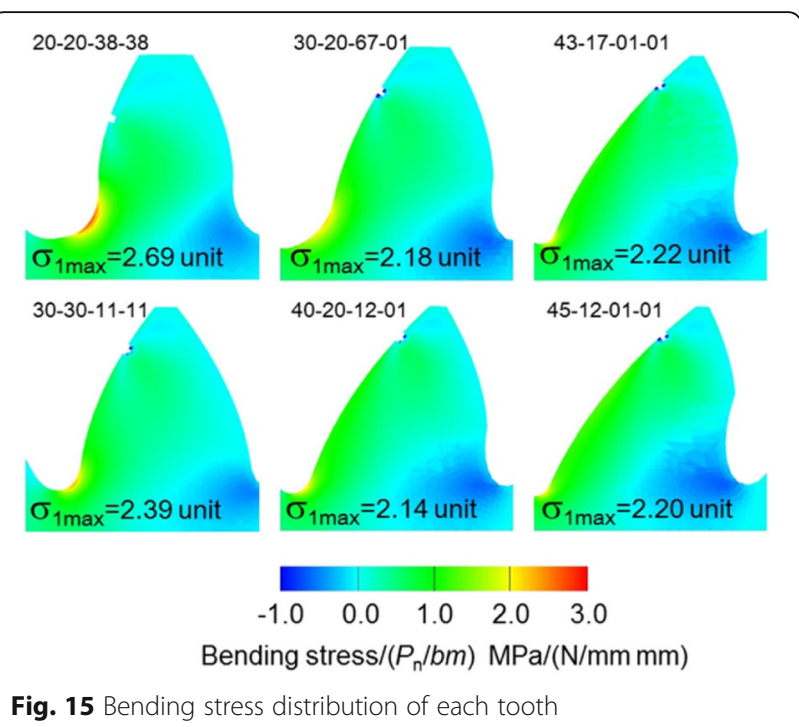

to the surface. In order to express the allowable stress for surface damage in terms of the Hertzian maximum stress $p_{\max }$, the formula was converted to Eq. (6) by using the relationship $\tau_{\mathrm{zx}}=0.25 p_{\max }$ (Yamamoto and Kaneta, 1998):

$$
\sigma_{H l i m}=4 \times \tau_{w}
$$

An allowable stress higher than the ISO value is shown, but this is due to defect sizes being estimated to be small and the ISO allowable stress erring on the side of comparative safety. Table 1 lists the allowable stresses.

\section{Evaluation of load capacity}

Allowable tooth normal loads $P_{\text {Fal }}$ and $P_{\text {Hal }}$ at which the bending stress and Hertzian contact stress, respectively, reach each allowable stress are found from the allowable stresses and FEM analysis using Eqs. (7) and (8):

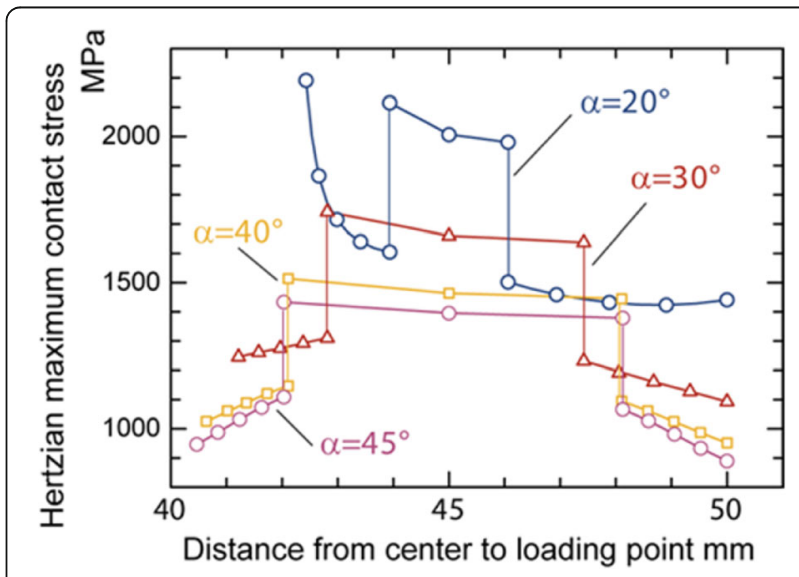

Fig. 16 Hertzian stress for various pressure angles considering load-sharing ratio 


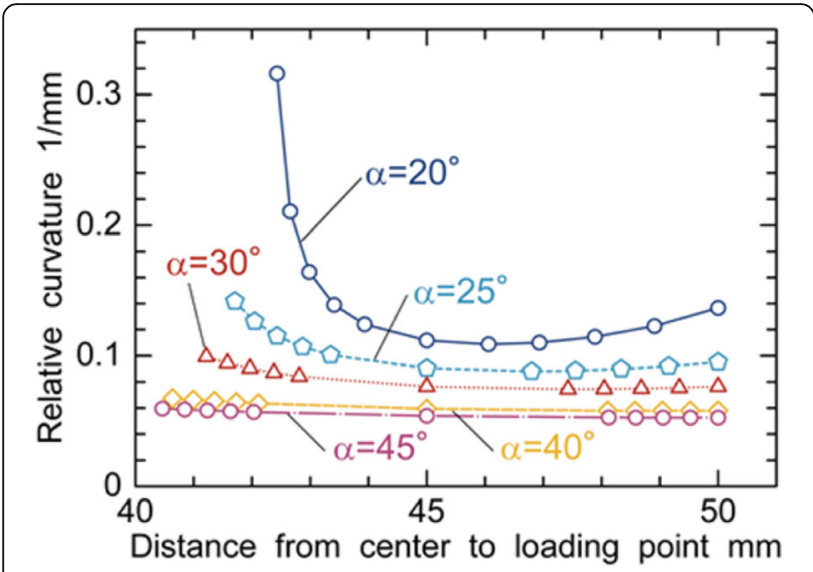

Fig. 17 Relative curvature for various pressure angles

$$
\begin{aligned}
P_{\text {Fal }} & =\frac{\sigma_{\text {Flim }}}{\sigma_{1 \max }} \\
P_{\text {Hal }} & =\frac{\sigma_{\text {Hlim }}^{2} \pi b\left(\frac{1-v_{1}^{2}}{E_{1}}+\frac{1-v_{2}^{2}}{E_{2}}\right)}{\frac{1}{R_{1}}+\frac{1}{R_{2}}}
\end{aligned}
$$

The normal vector loads are then converted into torques according to Eq. (9). We should note that when the pressure angle becomes large, the transmission torque decreases. Terms $T_{\mathrm{Fal}}$ and $T_{\mathrm{Hal}}$ express the allowable torques, namely the torque transmission capacity for bending and surface damage, respectively.

$$
T=P \cdot r_{b}=P \cdot \frac{m z}{2} \cos \alpha
$$

Figure 18 shows the relationship between pressure angle on the load side and allowable transmission torque. From this figure, we find that the increase in pressure angle of the load side works beneficially with respect to the contact pressure because of the increase in relative curvature radius. On the other hand, the highest torque capacity for bending is expected for the tooth profile with a $30^{\circ}$ pressure angle.

If $T_{\mathrm{Hal}}>T_{\mathrm{Fal}}$ for a given gear, then the tooth can be expected to be fractured by bending. If $T_{\mathrm{Fal}}>T_{\mathrm{Hal}}$, then surface damage can be expected to occur. Accordingly, for a gear manufactured from flame-hardened MQ class

Table 1 Material properties and allowable stresses

\begin{tabular}{llll}
\hline Material & $\mathrm{Hv}$ & $\sigma_{\text {Flim }}(\mathrm{MPa})$ & $\sigma_{\text {Hlim }}(\mathrm{MPa})$ \\
Flame-hardened MQ class & 500 & 360 & 1150 \\
Case-hardened ME class & $650-800$ & 525 & 1650 \\
Inclusion size $\sqrt{\boldsymbol{A}}(\mu \mathrm{m})$ & $\mathrm{Hv}$ & $\sigma_{\text {Flim }}(\mathrm{MPa})$ & $\sigma_{\text {Hlim }}(\mathrm{MPa})$ \\
50 & 600 & 600 & 2270 \\
50 & 800 & 760 & 2900 \\
\hline
\end{tabular}

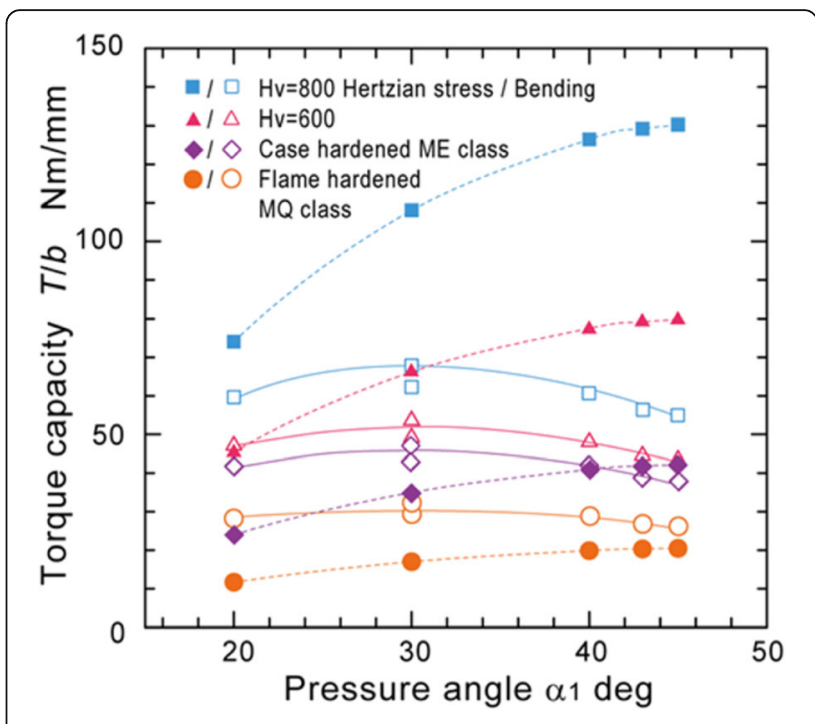

Fig. 18 Torque capacity for each tooth profile

steel, surface damage will probably occur with all forms. Also, the greatest torque transmission capacity can be expected to be demonstrated when the pressure angle on the meshing side is $45^{\circ}$. In the case of case-hardened ME class material, $T_{\mathrm{Fal}} \approx T_{\mathrm{Hal}}$ at a pressure angle of $40^{\circ}$. At pressure angles lower and higher than this, surface damage and bending fracture are expected to occur, respectively. If this material is used, the greatest torque transmission capacity will be at a pressure angle of $40^{\circ}$.

Similarly, for a material with $\sqrt{A}=50 \mu \mathrm{m}$ and hardness $=600 \mathrm{Hv}$, using a tooth for which the pressure angle becomes approximately $21^{\circ}$ puts the load capacity for bending and contact pressure in opposition. However, even if the pressure angle becomes larger, $T_{\text {Fal }}$ increases and a maximum torque transmission capacity can be expected at around $\alpha_{1}=30^{\circ}$. In the case of $\sqrt{A}=50 \mu \mathrm{m}$ and hardness $=800 \mathrm{Hv}, T_{\mathrm{Hal}}$ is larger than $T_{\mathrm{Fal}}$ for any tooth profile. So, a maximum torque transmission capacity can be expected at around $\alpha_{1}=30^{\circ}$, for which $T_{\text {Fal }}$ takes its maximum value.

\section{Conclusions}

In this paper, the strength of gears with asymmetric tooth profiles is discussed considering the load-sharing ratio, and the gear performance is evaluated in relation to the torque transmission capacity. Tooth pressure angles of $20^{\circ}$ to $45^{\circ}$ were analyzed.

The load-sharing ratio was determined from the calculation results of deflection by FEM analysis for ISO standard tooth forms and asymmetric tooth forms. No significant difference was found for the higher pressure angle tooth. 
Bending stress analysis was also performed by FEM analysis. The root stress in higher pressure angle teeth against unit load decreased because of the thick root of the tooth. However, the highest torque capacity for bending was expected for the tooth profile with a $30^{\circ}$ pressure angle because an increase of the pressure angle leads to a smaller base circle.

The durability against surface damage was evaluated in relation to Hertzian contact stress. In the case of a higher pressure angle tooth, the contact stress decreases with increasing relative radius of curvature. Furthermore, the Hertzian stress is proportional to the square root of the normal load. Therefore, the tooth with a pressure angle of $45^{\circ}$ has the maximum torque capacity for surface damage.

Assuming that the load capacity of a gear is determined by load capacity with respect to bending or load capacity with respect to contact pressure-whichever is lower-the greatest torque load capacity can be expected at $\alpha_{1}=45^{\circ}$ for all forms in the case of flame-hardened MQ class steel. The damage mode will probably be contact pressure damage.

For case-hardened ME class steel, the load capacity with respect to bending and the load capacity with respect to contact pressure are equivalent when $\alpha_{1}=40^{\circ}$, in which case the greatest load capacity can be expected.

For a material based on an original strength evaluation formula with $\sqrt{A}=50 \mu \mathrm{m}$ and hardness $=600 \mathrm{Hv}$, the strength with respect to contact pressure is low at $\alpha_{1}=20^{\circ}$. However, the load capacity with respect to contact pressure and the load capacity with respect to bending are reversed as $\alpha_{1}>21^{\circ}$. At $\sqrt{A}=50 \mu \mathrm{m}$ and hardness $=800 \mathrm{Hv}$, the load capacity with respect to bending is low for all pressure angles. This means that the greatest load capacity can be expected when $\alpha_{1}=30^{\circ}$, both with respect to bending and with respect to contact pressure.

This result indicates that a large load surface pressure angle is good for low-strength materials and a small pressure angle is good for high-strength materials. For materials with moderate strength, an optimal pressure angle is assumed to exist that realizes both load capacity with respect to bending and load capacity with respect to contact pressure.

\section{Acknowledgements}

The authors would like to gratefully thank Dr. Yasunari Mimura for helping us to perform the FEM analysis. We also acknowledge the financial support from the Promotion Association of Tsuruoka College.

\section{Authors' contributions}

Both authors read and approved the final manuscript.
Received: 21 August 2016 Accepted: 27 October 2016

Published online: 11 November 2016

\section{References}

Deng, G., Nakanishi, T., \& Inoue, K. (2003). Bending load capacity enhancement using an asymmetric tooth profile. JSME International Journal Series $C$, 46(3), 1171-1177.

ISO 53:1998(E), Cylindrical gears for general and heavy engineering—standard basic rack tooth profile.

ISO 6336-5:2003(E), Calculation of load capacity of spur and helical gears-part 5: strength and quality of materials.

Kapelevich, A. (2000). Geometry and design of involute spur gears with asymmetric teeth. Mechanism and Machine Theory, 35(1), 117-130.

Kapelevich AL (2013). Direct gear design, March 22, 2013, Boca Raton: by CRC Press.

Kapelevich, A, Shekhtman, Y. (2009). Tooth fillet profile optimization for gears with symmetric and asymmetric teeth. Geartechnology, 73-79. http://www. geartechnology.com/articles/0909/Tooth_Fillet_Profile_Optimization_for_ Gears_with_Symmetric_and_Asymmetric_Teeth.

Kapelevich, L, Shekhtman, W. (2016). Rating of asymmetric tooth gears. Power Transmission Engineering, 40-45. http://www.powertransmission.com/articles/ 0416/Rating_of_Asymmetric_Tooth_Gears/.

Kruger, D, Romhild, I, Linke, H, Brechling, J, Hess, R (2013). Increasing the load capacity of gear teeth by asymmetric gear tooth design, International Conference on Gears 2013, VDI-Berichte Nr. 2199, 1327-1340.

Litvin, F. L., Lian, Q., \& Kapelevich, A. L. (2000). Asymmetric modified gear drives: reduction of noise, localization of contact, simulation of meshing and stress analysis. Computer Methods in Applied Mechanics and Engineering, 188(2000), 363-390.

Masuyama, T., Kato, M., Inoue, K., \& Yamashita, T. (2002). Evaluation of bending strength of carburized gears based on a quantification of defect size in the surface layer, transactions of the ASME. Journal of Mechanical Design, 124-3, 533-538.

Masuyama, T., Mimuta, Y., \& Inoue, K. (2015). Bending strength simulation of asymmetric involute tooth gears. Journal of Advanced Mechanical Design Systems, and Manufacturing, 9(5), 11.

Murakami, Y (2002). Metal fatigue: effects of small defects and nonmetallic inclusions. Amsterdam: Elsevier Science Ltd.

Narita, Y., Yamanaka, M., Kazama, T., Osafune, Y., \& Masuyama, T. (2013). Simulation of rolling contact fatigue strength for traction drive elements. Journal of Advanced Mechanical Design Systems and Manufacturing, 7(3), 432-447.

Taniguchi, T (1992). Automatically meshing for finite element method. Tokyo: Morikita Publishing Co., Ltd., (in Japanese).

Yamamoto, Y, Kaneta, M. (1998). Tribology. Tokyo: Riko-gakusha Publishing Co., Ltd., (in Japanese).

\section{Submit your manuscript to a SpringerOpen ${ }^{\odot}$ journal and benefit from:}

- Convenient online submission

- Rigorous peer review

- Immediate publication on acceptance

- Open access: articles freely available online

- High visibility within the field

- Retaining the copyright to your article

Submit your next manuscript at springeropen.com 